\title{
Establishing a center of excellence in abdominal wall reconstruction
}

\author{
Jenny Shao, Sharbel Elhage, Eva Deerenberg, Vedra Augenstein, B. Todd Heniford \\ Gastrointestinal and Minimally Invasive Surgery, Department of Surgery, Carolinas Medical Center, Charlotte, NC 28204, USA.
}

Correspondence to: Dr. B. Todd Heniford, Gastrointestinal and Minimally Invasive Surgery, Department of Surgery, 1025 Morehead Medical Drive Suite 300, Charlotte, NC 28204, USA. E-mail: todd.heniford@gmail.com

How to cite this article: Shao J, Elhage S, Deerenberg E, Augenstein V, Heniford BT. Establishing a center of excellence in abdominal wall reconstruction. Plast Aesthet Res 2020;7:21. http://dx.doi.org/10.20517/2347-9264.2020.04

Received: 3 Jan 2020 First Decision: 10 Apr 2020 Revised: 13 Apr 2020 Accepted: 16 Apr 2020 Published: 25 Apr 2020

Science Editor: Sahil Kuldip Kapur Copy Editor: Jing-Wen Zhang Production Editor: Tian Zhang

\begin{abstract}
Building a tertiary referral center of excellence for complex abdominal wall reconstruction is a multi-step process that requires many elements to garner and promote success. Ultimately the creation of such a center is important for continual improvement of abdominal wall reconstruction outcomes by decreasing complications, recurrences, length of hospital stay, hospital readmissions, and overall costs. Establishing a center of excellence incorporates several key components including the surgeon's desires and expertise, institutional participation, multidisciplinary collaboration, outcomes research and innovation, and financial stability. This article outlines the principal elements of building a sustainable, functional, and successful center of excellence for complex abdominal wall reconstruction.
\end{abstract}

Keywords: Complex abdominal wall reconstruction, center of excellence

\section{INTRODUCTION}

Over 1 million hernia surgeries are performed in the United States annually, making hernia repair the most common general surgery procedure performed by surgeons across the country ${ }^{[1-3]}$. Hernias occur due to a variety of factors, including prior abdominal surgery, increased intraabdominal pressure secondary to chronic cough or obesity, and compromised connective tissue integrity as a result of genetics, infection and other factors. The incidence of abdominal hernia needing surgery is estimated to be as high as $20 \%-30 \%$ in the literature ${ }^{[4-7]}$. Due to the large number of patients requiring hernia repair, it is estimated that a $1 \%$ reduction in hernia recurrence would save $\$ 32$ million annually in healthcare ${ }^{[1]}$. While personal health consequences are supremely important, these data highlight the significant financial implications for both hospitals and patients in hernia prevention and durability of repair. Of those patients undergoing 
ventral hernia repair, it is estimated that as many as $12 \%-52 \%$ will have a hernia recurrence, which ultimately leads to more surgery, reduced quality of life, prolonged recovery, a greater chance of future failure, and increasing healthcare $\operatorname{costs}^{[8-12]}$. It is estimated that each failed hernia repair results in higher morbidity, cost, and risk of recurrence for each subsequent repair ${ }^{[13-15]}$. All these factors combined make a compelling argument for optimizing the index hernia repair for patients to decrease recurrence rates and cost, ultimately improving patient outcomes. This leads to preoperative optimization of modifiable patient comorbidities, increasing patient education, and streamlining operative and postoperative factors to provide the best care.

\section{BUILDING A CENTER OF EXCELLENCE}

\section{What does it mean to be a center of excellence?}

The trend towards building "centers of excellence" is not a new concept in surgery. Within recent years, driven by national policies considering outcome measures, there has been a drive towards improved outcomes and decreased complications, length of hospital stay, and hospital readmissions ${ }^{[16,17]}$. This is backed by data and evidence from across many surgical specialties, including oncologic, bariatric, orthopedic, and cardiovascular surgery, in which better surgical outcomes are seen at established high-volume specialized centers $^{[18-28]}$. The trend of improved outcomes at high-volume specialty centers is especially noticeable for complex procedures. While the current literature does not provide a full explanation for this association, the improvement in outcomes is likely linked to an increased surgical skill set from high-volume repetition (practice makes perfect model), selective-referral patterns, and accessibility to additional specialized resources for more comprehensive perioperative care ${ }^{[27]}$. The literature also demonstrates that associated surgical fellowships also improve surgical outcomes ${ }^{[29-31]}$. This is most ardently demonstrated in bariatric surgery, which has reinforced the development of a bariatric center of excellence $(\mathrm{COE})^{[32,33]}$. The term COE has been widely adopted by many fields of surgery, but what does it truly mean to be a COE? This article will describe the foundations of a COE for complex abdominal wall reconstruction (AWR) and the key components needed to build a multidisciplinary practice centered on improvement of patient outcomes and development of new techniques for advancement of surgical practice.

\section{Establishing a multidisciplinary AWR center}

Establishing a tertiary referral and care center for AWR is a concept that has solidified in the past decade ${ }^{[17,34-36]}$. Recognition of hernia surgery as a challenging endeavor fraught with unique challenges has led to the development of several specialized AWR centers ${ }^{[34-36]}$. There is a paucity of literature available regarding which healthcare systems would qualify as a COE. From the literature, we see how the German Hernia Society has created a 3-tier accreditation system for hernia repair centers, stratifying centers based on volume, outcome evaluation, academic involvement, hernia research, and participation in multicenter databases ${ }^{[37]}$. In addition to traditional measures of success, such as hernia recurrence and pure clinical outcomes, there is a push to include patient quality of life, focus on research, and continual participation in ongoing academics to bolster the current advancements in surgery ${ }^{[37]}$. Williams et al ${ }^{[35]}$ described the establishment of a hernia referral center, which led to an increase in the complexity of the patients referred, including a $48 \%$ increase in recurrent hernias, increasing patient comorbidities, and overall complexity. Raigani et al. ${ }^{[36]}$ describe a similar trend of increasing complexity in 2014, in which patients traveling over 100 miles were more likely to have active mesh infections and increased length of stay. Both studies highlight that increasing hernia complexity combined with patient comorbidity and operative difficulty should lead to increasing postoperative complications. However, in practice, complex patients treated at tertiary referral centers do not have a proportional increase in adverse outcomes or complications due to expertise provided at these centers ${ }^{[35,36]}$.

The European Hernia Society has also developed an expert consensus comprising 18 surgeons across Europe to form the ACCESS Group (Hernia Accreditation and Certification of Centers and Surgeons - 
Working Group) to formulate scientifically based requirements for hernia centers and hernia specialists ${ }^{[38]}$. They propose that an adequately prepared hernia center will have the following components: accredited/ certified by a national or international hernia society, perform higher case volume hernia surgery compared to average, experienced surgeons beyond their learning curve, evidence-based clinical treatment, document outcomes in hernia registry or database, and perform follow-up comparisons of outcomes with benchmark data for continual improvement ${ }^{[38]}$. These recommended requirements have been put forth so that healthcare systems can develop their own programs, while taking into account specific healthcare system constraints $^{[38]}$.

At the authors' own institution, a hernia center has been established since 2004, due to increasing patient numbers, complexity of abdominal wall hernias, and outside referrals. Since that time, a growing network of general surgeons, plastic surgeons, infectious disease specialists, allergists, radiologists, orthopedic surgeons, geriatricians, and sports medicine, research, and support staff have been recruited in a multidisciplinary fashion to coordinate complex care for patients. This coordinated problem-solving approach has allowed the hospital system to increase annual case volume by $234 \%$, annual billing by $713 \%$, in-state referrals by $340 \%$, and out of state referrals by $540 \%{ }^{[35]}$. Using a model of concentrated, high-quality patient-centered, patient-specific care in both the inpatient and outpatient setting has led to a streamlined perioperative process that reduces preoperative modifiable comorbidities, increases patient education and high-volume technical operations, combined with specific goal-oriented postoperative management strategies, and ultimately smooth transitions of care. All these combined efforts have led to decreasing recurrence rates and improved patient outcomes and quality of life ${ }^{[39]}$. This comprehensive care has also allowed for continued academic improvement and research, to analyze outcomes for further improvement.

Regardless of the approach, whether a government-driven model like the one in Germany or a surgeondriven model such as at the authors' institution, they both emphasize similar core characteristics encompassing high-quality, financially sustainable, multidisciplinary care, with the ability for continual improvement through academic research and outcomes analysis. An AWR COE should be able to confer the benefits of the institution to the patient in a standardized manner with reproducible and reliable outcomes for complex hernia patients. Cherla et al. ${ }^{[40]}$ described a significant reduction in surgical site infections in over 600 patients from 13.5 to $1.5 \%$ over a period of one year, despite increasing complexity of cases, due to appropriate patient referral, improved preoperative management of patient comorbidities, and internal consistency of treatment principles across all surgeons participating in AWR. The true hallmark of a COE is the ability to mitigate increasing risk factors in complex patients and still provide successful clinical outcomes with low hernia recurrence, infections, length of stay, and cost, while simultaneously improving quality of life.

While no strict criteria exist indicating which patients should be referred to a AWR COE, some general considerations that may warrant referral are: surgeon experience and comfort performing hernia operations, patient complexity including presence of mesh infections or fistulas, loss of domain, need for components separation technique, lack of hospital resources such as Botox and plastic surgery, and multiple recurrent hernias with many prior operations. Ultimately, referral is dependent on a recognition for a higher level of care due to increasing patient complexity and the ability of a COE to provide patientspecific care with improved hernia outcomes and decreased recurrence rates ${ }^{[27,35,36,39,40]}$.

Having a COE is beneficial not only to patients but to parent institutions as well by increasing surgical volume, complexity, and reputational benefits, which will draw additional resources and talent and expand the infrastructure already implemented. Additionally, the treatment of a large volume of patients, as seen at our institution, can be and has been the driving force for innovative research focusing on preoperative optimization, operative techniques, and postoperative quality of life. Integration of academic research in 
AWR allows for quality improvement as institutions can follow their own long-term outcomes for selfevaluation, and eventual growth and improvement.

\section{KEY COMPONENTS OF A SUCCESSFUL HERNIA CENTER}

There are several key components that all successful tertiary care AWR COEs will require: surgeon experience and expertise, support of parent institution, interdisciplinary collaboration, commitment to current evidence-based practice and continual outcome assessment, and financial stability.

\section{Surgical expertise}

Operative technique and anatomical mastery

Education and specialization in AWR and hernia surgery with good operative technique is a foundational building block of a successful hernia center. As with many other experts in their respective fields, practice makes perfect and having the appropriate experience and training is important in $\mathrm{AWR}^{[27,28]}$. Surgeons specializing in AWR may have training in general, minimally invasive, robotic, and plastic surgery, or a combination of all these techniques in their armamentarium. Proper knowledge of the relevant anatomy and of the appropriate surgical technique and tissue planes cannot be understated to perform the optimal surgery, and the ability to innovate and create new techniques for hernia repair is also important. Once mastery is achieved, continued education and involvement in academic research and conferences are also important to sustain a level of high-quality care. Having surgical fellows and training programs also fosters excellence within a center and improves outcomes ${ }^{[29-31]}$. Attending and hosting AWR courses can also be utilized as a tool for maintaining expertise.

\section{Perioperative management}

In addition to the appropriate technical skills, surgeons must also possess the clinical acumen to provide appropriate perioperative care for complex AWR patients. Being able to successfully navigate complex patient records with multiple prior abdominal surgeries, complications, and hernia repairs is very helpful in formulating the next clinical care steps. Routinely, outside hospital records and CT scans are obtained. Once an assessment has been made, along with a thorough history and physical examination, identification of the patient's specific risk factors is made, and pre-habilitation as needed precedes surgery ${ }^{[39]}$. Sometimes, a patient may not be ready for surgery for several months after their initial consultation to optimize their specific comorbidities.

Risk models commonly used include the Ventral Hernia Risk Score, the Ventral Hernia Working Group Grade, Centers of Disease Control and Prevention Wound Class, and Hernia Wound Risk Assessment tool. An application designed by our institution known as the Carolinas Equation for Determining Associated Risks is commonly employed to calculate a patient's postoperative cost and risk of wound complications $^{[41-45]}$. Utilization of this application has decreased cost and wound complications specific to our center and has been recognized across the world as an accurate predictor of risk ${ }^{[46]}$.

Specifically, the risk factors and comorbidities addressed by the assessments are geared towards prevention of hernia recurrence, need for additional surgery, prevention of complications, and decreasing $\operatorname{costs}^{[39,45,46]}$. To accomplish this goal, associated complications or comorbidities that contribute to recurrence such as infection, obesity, tobacco use, and diabetes are factors that warrant careful attention. Having a comprehensive approach to patient care and tailored patient counseling prior to surgery is an important keystone in the patients' postoperative course and outcomes. Optimization is not limited to informing patients about their risk, it also includes patient-specific interventions and confirmation of success.

Strategies for optimization include weight loss for patients who are obese with BMI $\geq 30 \mathrm{~kg} / \mathrm{m}^{2}$ by not only providing patient education, but also dietary plans, multidisciplinary follow-up with bariatric dieticians, 
establishing specific weight loss goals, and follow-up appointments with healthcare providers prior to scheduling surgery. Smoking cessation is mandatory and confirmed with nicotine tests on follow-up clinic visits and prior to surgery. Glycemic control defined as a hemoglobin A1c less than $7.2 \%$ is used on the basis of internal validation for risk calculations as well as international consensus ${ }^{[47-51]}$. All these interventions are achieved through a healthcare network in conjunction with a multidisciplinary team involving the primary care provider, dietician, bariatricians, bariatric surgeons, and other healthcare providers. Ultimately, these efforts are geared towards preventing wound complications postoperatively, since obesity, active smoking, and diabetes are all independent predictors for increasing wound complications and recurrence in AWR patients ${ }^{[39,47-54]}$. In addition, patients also undergo preoperative screening to make sure all preoperative work up is completed from a cardiopulmonary and anesthesia standpoint.

Patients who have had multiple hernia surgeries also undergo preoperative CT scans to assess hernia defect size and better understand surgical anatomy. Often, prior meshes, as well as other abnormalities that may impact the surgery are seen on CT and can be used for perioperative planning. In patients who have large defect sizes and loss of domain that may make fascial closure difficult, they can be considered for preoperative botulinum toxin injection and be counseled concerning the need for components separation. Preoperative planning for success is perhaps the most important component to providing a successful surgery. Appropriate patient selection, risk factor modification, and sound surgical planning prior to a procedure is crucial to a successful index operation or durable recurrent hernia repair.

\section{Institutional participation}

Building a hernia COE requires many resources and buy in from all participants, most importantly from the parent institution. Understanding the value of having a hernia COE and the additional value it brings to an institution will allow the parent institution to participate, promote and use available resources to bring recognition to the AWR center ${ }^{[55]}$.

\section{Creating visibility}

Marketing and creating a presence through advertising by various means will help facilitate referrals and increase patient volume. Additional promotion should include a dedicated website and social media presence, featured articles in local media, press releases, distribution of brochures, peer-reviewed publications, national conference presentation and recognition, and education of other healthcare providers within the system to increase the referral base.

\section{Dedicated ancillary support}

Other keys to making a successful COE is having dedicated personnel specific to the program who can espouse the key principles of the hernia center and who understand how to support the program and help it grow. These are a team of advanced care practitioners (nurse practitioners and physician assistants) who are trained to specifically take care of hernia patients, surgical schedulers with knowledge of operative needs, insurance and billing specialists to help obtain coverage and payment for specific interventions that are hernia specific. In an academic center, having designated research personnel and statisticians, as well as staff assistants and coordinators are also important and can significantly improve care by simply associating behavior and outcomes in the center.

\section{Coordination of care}

Having a nationally renowned AWR center with a wide referral base also means attracting patients from a larger catchment area with patients traveling from out of state for consultation, perioperative care, and surgery. Being able to coordinate alignment of clinic times for multiple consultants, operative scheduling and travel plans, and allowing for smooth integration of care in a new healthcare system by obtaining prior medical records and imaging are all tasks that will need to be completed for successful and streamlined care. 


\section{Interdisciplinary collaboration}

Building a network of specialists

Surgery alone is not enough for success in complex AWR patients who often will require a multi-faceted approach to ensure they are prepared, optimized, and ultimately ready to undergo surgery. As previously discussed, having a support network of ancillary staff and physicians with aligned goals in a coordinated effort is essential. Building a network of physicians who intimately understand the unique challenges that AWR patients face and how to intervene in these problems will be beneficial.

\section{Potential areas of collaboration}

Much of specialist collaboration is planned prior to the operation by recognizing areas of improvement. Preoperative consultation of bariatricians, dieticians, primary care doctors, and endocrinologists to help with management of comorbidities including weight loss, glycemic control, and smoking cessation is important. There should be consideration of a prior history of thromboembolism and the use of anticoagulation medications. This would would lead to decisions concerning which patients would benefit from an inferior vena cava filter and the management of anticoagulated medications to limit the risk of adverse events including stroke, pulmonary embolism, while attempting to mitigate the chance of postoperative bleeding or hematoma. Consulting with radiology regarding CT scan findings can be helpful to decide which patients with larger hernia defects would benefit from preoperative Botox injection ${ }^{[56]}$. Radiologists can also participate greatly in drain placement, injection of steroids or other drugs in specific areas, and diagnosis and management of pain in patients. Patients might also benefit from a consult with plastic surgery regarding advancement flaps or perhaps the need for concomitant panniculectomy during the hernia repair itself. Some patients may also need simultaneous intraabdominal procedure such as enterocutaneous fistula takedown, biliary surgery, colon resection, ostomy revision or reversal, etc., and having the appropriate consulting surgeons available is necessary. Other patients who have had prior hernia repairs with complications of prior or existing infection or have extensive antibiotic allergies may also benefit from an infectious disease consult.

Intraoperatively, having an anesthesia team focused on multimodal pain management is extremely helpful to limit postoperative narcotic requirement, improve postoperative mobility, and ultimately reduce the length of hospital stay ${ }^{[57-59]}$. Setting forth an intraoperative protocol for pain management including the use of a lidocaine drip, dexmedetomidine, and liposomal bupivicaine by performing transversus abdominis plane blocks will be helpful in terms of limiting overall narcotic use (ERAS). Postoperative use of patientcontrolled analgesia, early mobility, and introduction of scheduled Tylenol, gabapentin, and ibuprofen will also be key to decreasing ileus, decreasing narcotic use, and decreasing hospital length of stay ${ }^{[57-59]}$.

Postoperative consultation with geriatricians to manage older patients with frailty, limited mobility, declining mental status, and polypharmacy can significantly improve the postoperative recovery process for that subset of patients ${ }^{[60]}$. Managing inpatient and outpatient complications will also be important as the need arises. Also necessary will be utilizing resources of interventional radiology to drain any postoperative fluid collection, consultation with infectious disease physicians for treatment of surgical site occurrences, the need for physical therapy and social work, and rarely the need for intensivist care or other subspecialists.

The underlying vital concept is to generate harmony between care teams, and that predominantly relies on leadership, adequate communication of ideas and responsibilities, and a healthy relationship between all members of the healthcare network. Indeed, identifying experts and leaders in each field will influence the success of a patient's ultimate outcome and success of the AWR center. Great teamwork with careful coordination is indispensable in a well-run and organized complex AWR COE. 


\section{Outcomes research and innovation}

Analysis of outcomes and participation in clinical research has been demonstrated to have an association with improved postoperative outcomes. Involvement in multicenter hernia registry has also been linked to improved outcomes due to awareness of surveillance (Hawthorne effect), or self-selection bias in which participating centers have higher vested interest in overall hernia outcomes ${ }^{[37,38,61,62]}$. The ability to maintain a prospective database with long-term analysis of hernia recurrence rates, quality of life, and postoperative outcomes is the only way to understand if implemented techniques and interventions achieve their goal and meet patient satisfaction ${ }^{[63-66]}$.

Promotion of a rich research environment by having a diverse group of research personnel for each step of the process will streamline data collection, consent of patients, institutional review board approval, data analysis, and ultimately abstract submissions, presentations, and preparation of manuscripts for publication. These tasks can be done with dedicated research staff including research managers, data collection specialists, residents, and fellows. Having a surgical fellowship encourages continual learning, improvement, introduction of new techniques and the ability to sustain academic productivity ${ }^{[29-31]}$. In many ways, academic research can complement a clinically busy workload. Research can also be funded by obtaining sponsors and grants, including but not limited to national sponsors (National Institutes of Health, Department of Defense), surgical associations, industry, and hospital-specific internal funding.

Collaboration with other hernia centers encourages shared learning, data collection, and increased statistical power. It also allows for the identification of reproducible outcomes that can then be generalized. Participation in hernia registries can go a long way in terms of gaining new data and information. Collaboration can be more formalized through registered databases, at national and international academic meetings, but it can also be informal through social media and other various idea and information sharing platforms.

\section{Financial independence and sustainability}

The financial investment needed for establishing an AWR COE can be substantial but will be offset by the financial benefits of having a tertiary care referral center that will generate revenue from a growing patient network, referral patterns, and decreasing cost of complications, recurrence, and reoperations. Negotiation of resources is unique in each institution and building a COE will be a long-term investment that will ultimately improve the reputation of the parent institution, establish patient care practices that will decrease postoperative cost, length of stay and financial burden of complex patients. Building a sustainable and streamlined process only leads to a more efficient and cost-effective system that focuses on decreasing healthcare costs. A recent review demonstrated that by modifying risk factors alone in over 700 patients, there was a decrease in postoperative wound-related complications from $40.8 \%$ to $20.6 \%$, with an estimated savings of over $\$ 4$ million $^{[46]}$. Postoperative billing should also reflect the complexity of the work performed by the healthcare team and should consider recurrence, incarceration, mesh excisions, components separation, and documentation of advancement flaps and soft tissue rearrangements needed after the hernia repair itself. These combined interventions of generating referral patterns, increasing productivity in clinical activity, research reputation, and decreasing healthcare costs are worthwhile institutional investments.

\section{CONCLUSION}

The marker of a successful AWR program is multifactorial with many key components. In a system that works well, all participants should collaborate and benefit from the COE, including the institution, surgeons, physicians, care providers, and above all the patients. Increased case volume, complexity and referrals together will be one indication of success, but other measurable indicators include long-term patient outcomes and hernia recurrence rates. 


\section{DECLARATIONS}

\section{Acknowledgments}

The intention of this article is to provide building blocks and a foundation for the successful establishment of a hernia specialty center. Any changes in referral or influence are secondary and unintended.

\section{Authors' contributions}

Made substantial contributions to conception and design of the study and performed data analysis and interpretation: Shao J, Elhage S, Deerenberg E, Augenstein V, Heniford BT

\section{Availability of data and materials}

Not applicable.

\section{Financial support and sponsorship}

None.

\section{Conflicts of interest}

Dr. Heniford has received honoraria and research support from Allergan, W. L. Gore, and Stryker. Dr. Augenstein has received consultation fees from W. L. Gore, Allergan, and KCI. The authors have no other relevant financial or personal relationships that could inappropriately influence this work or its conclusions. None of the authors has a financial interest in any of the products, devices or drugs mentioned in the article.

\section{Ethical approval and consent to participate}

Not applicable.

\section{Consent for publication}

Not applicable.

\section{Copyright}

(c) The Author(s) 2020.

\section{REFERENCES}

1. Poulose BK, Shelton J, Phillips S, Moore D, Nealon W, et al. Epidemiology and cost of ventral hernia repair: making the case for hernia research. Hernia 2012;16:179-83.

2. Rutkow IM. Demographic and socioeconomic aspects of hernia repair in the United States in 2003. Surg Clin North Am 2003;83:1045-51.

3. Colavita PD, Tsirline VB, Walters AL, Lincourt AE, Belyanksy I, et al. Laparoscopic versus open hernia repair: outcomes and sociodemographic utilization results from the nationwide inpatient sample. Surg Endosc 2013;27:109-17.

4. Deerenberg EB, Harlaar JJ, Steyerberg EW, Lont HE, van Doorn HC, et al. Small bites versus large bites for closure of abdominal midline incisions (STITCH): a double-blind, multicentre, randomised controlled trial. Lancet 2015;386:1254-60.

5. Jairam AP, Timmermans L, Eker HH, Pierik REGJM, van Klaveren D, et al. Prevention of incisional hernia with prophylactic onlay and sublay mesh reinforcement versus primary suture only in midline laparotomies (PRIMA): 2-year follow-up of a multicentre, double-blind, randomised controlled trial. Lancet 2017;390:567-76.

6. Aquina CT, Rickles AS, Probst CP, Kelly KN, Deeb AP, et al. Visceral obesity, not elevated BMI, is strongly associated with incisional hernia after colorectal surgery. Dis Colon Rectum 2015;58:220-7.

7. Trimbos JB, Smit IB, Holm JP, Hermans J. A randomized clinical trial comparing two methods of fascia closure following midline laparotomy. Arch Surg 1992;127:1232-4.

8. Davila DG, Parikh N, Frelich MJ, Goldblatt MI. The increased cost of ventral hernia recurrence: a cost analysis. Hernia 2016;20:811-7.

9. van Ramshorst GH, Eker HH, Hop WC, Jeekel J, Lange JF. Impact of incisional hernia on health-related quality of life and body image: a prospective cohort study. Am J Surg 2012;204:144-50.

10. Hesselink VJ, Luijendijk RW, de Wilt JH, Heide R, Jeekel J. An evaluation of risk factors in incisional hernia recurrence. Surg Gynecol Obstet 1993;176:228-234.

11. Stoppa RE. The treatment of complicated groin and incisional hernias. World J Surg 1989;13:545-554. 
12. Luijendijk RW, Hop WC, van den Tol MP, de Lange DC, Braaksma MM, et al. A comparison of suture repair with mesh repair for incisional hernia. N Engl J Med 2000;343:392-8.

13. Flum DR, Horvath K, Koepsell T. Have outcomes of incisional hernia repair improved with time? A population-based analysis. Ann Surg 2003;237:129-35.

14. Heniford BT, Park A, Ramshaw BJ, Voeller G. Laparoscopic repair of ventral hernias: nine years' experience with 850 consecutive hernias. Ann Surg 2003;238:391-9.

15. Reynolds D, Davenport DL, Korosec RL, Roth JS. Financial implications of ventral hernia repair: a hospital cost analysis. J Gastrointest Surg 2013;17:159-66.

16. Ibrahim AM, Hughes TG, Thumma JR, Dimick JB. Association of hospital critical access status with surgical outcomes and expenditures among medicare beneficiaries. JAMA 2016;315:2095-103.

17. Colavita PD, Walters AL, Tsirline VB, Belyansky I, Lincourt AE, et al. The regionalization of ventral hernia repair: occurrence and outcomes over a decade. Am Surg 2013;79:693-701.

18. Birkmeyer JD, Siewers AE, Finlayson EV, Stukel TA, Lucas FL, et al. Hospital volume and surgical mortality in the United States. N Engl J Med 2002;346:1128-37.

19. Champion JK, Pories WJ. Centers of excellence for bariatric surgery. Surg Obes Relat Dis 2005;1:148-51.

20. Cress D, Pelton J, Thayer SC, Bukrey C. Development of a center of excellence for joint replacement. Orthop Nurs 2010;29:150-68.

21. Hollenbeak CS, Rogers AM, Barrus B, Wadiwala I, Cooney RN. Surgical volume impacts bariatric surgery mortality: a case for centers of excellence. Surgery 2008;144:736-43.

22. Sharma A, Mehrotra M, Khullar R, Soni V, Baijal M, et al. Laparoscopic ventral/incisional hernia repair: a single centre experience of 1,242 patients over a period of 13 years. Hernia 2011;15:131-9.

23. Mehrotra A, Sloss EM, Hussey PS, Adams JL, Lovejoy S, et al. Evaluation of centers of excellence program for knee and hip replacement. Med Care 2013;51:28-36.

24. Begg CB, Cramer LD, Hoskins WJ, Brennan MF. Impact of hospital volume on operative mortality for major cancer surgery. JAMA 1998;280:1747-51.

25. Fong Y, Gonen M, Rubin D, Radzyner M, Brennan MF. Long-term survival is superior after resection for cancer in high-volume centers. Ann Surg 2005;242:540-7.

26. Luft HS, Bunker JP, Enthoven AC. Should operations be regionalized? The empirical relation between surgical volume and mortality. N Engl J Med 1979;301:1364-9.

27. Luft HS, Hunt SS, Maerki SC. The volume-outcome relationship: practice-makes-perfect or selective-referral patterns? Health Serv Res 1987;22:157-82.

28. Shahian DM, Normand SL. The volume-outcome relationship: from Luft to Leapfrog. Ann Thorac Surg 2003;75:1048-58.

29. Kohn GP, Galanko JA, Overby DW, Farrell TM. High case volumes and surgical fellowships are associated with improved outcomes for bariatric surgery patients: a justification of current credentialing initiatives for practice and training. J Am Coll Surg 2010;210:909-18.

30. Kim PS, Telem DA, Altieri MS, Talamini M, Yang J, et al. Bariatric outcomes are significantly improved in hospitals with fellowship council-accredited bariatric fellowships. J Gastrointest Surg 2015;19:594-7.

31. Altieri MS, Yang J, Yin D, Frenkel C, Talamini M, et al. Presence of a fellowship improves perioperative outcomes following hepatopancreatobiliary procedures. Surg Endosc 2017;31:2918-24.

32. Livingston EH. Surgical volume impacts bariatric surgery mortality: a case for bariatric surgery centers of excellence. Surgery 2010;147:751-3.

33. Ibrahim AM, Ghaferi AA, Thumma JR, Dimick JB. Variation in outcomes at bariatric surgery centers of excellence. JAMA 2017;152:629-36

34. Gilbert AI, Graham MF, Young J, Patel BG, Shaw K. Closer to an ideal solution for inguinal hernia repair: comparison between general surgeons and hernia specialists. Hernia 2006;10:162-8.

35. Williams KB, Belyansky I, Dacey KT, Yurko Y, Augenstein VA, et al. Impact of the establishment of a specialty hernia referral center. Surg Innov 2014;21:572-9.

36. Raigani S, De Silva GS, Criss CN, Novitsky YW, Rosen MJ. The impact of developing a comprehensive hernia center on the referral patterns and complexity of hernia care. Hernia 2014;18:625-30.

37. Köckerling F, Berger D, Jost JO. What is a certified hernia center? The example of the German hernia Society andGerman Society of General and Visceral Surgery. Front Surg 2014;1:26.

38. Köckerling F, Sheen AJ, Berrevoet F, Campanelli G, Cuccurullo G, et al. Accreditation and certification requirements for hernia centers and surgeons: the ACCESS project. Hernia 2019;23:185-203.

39. Cox TC, Blair LJ, Huntington CR, Colavita PD, Prasad T, et al. The cost of preventable comorbidities on wound complications in open ventral hernia repair. J Surg Res 2016;206:214-22.

40. Cherla DV, Holihan JL, Flores-Gonzalez JR, Lew DF, Escamilla RJ, et al. Decreasing surgical site infections after ventral hernia repair: a quality-improvement initiative. Surg Infect (Larchmt) 2017;18:780-6.

41. Liang MK, Goodenough CJ, Martindale RG, Roth JS, Kao LS. External validation of the ventral hernia risk score for prediction of surgical site infections. Surg Infect (Larchmt) 2015;16:36-40.

42. Berger RL, Li LT, Hicks SC, Davila JA, Kao LS, et al. Development and validation of a risk-stratification score for surgical site occurrence and surgical site infection after open ventral hernia repair. J Am Coll Surg 2013;217:974-82.

43. Breuing K, Butler CE, Ferzoco S, Hultman CS, Kilbridge JF, et al; Ventral Hernia Working Group. Incisional ventral hernias: review of 
the literature and recommendations regarding the grading and technique of repair. Surgery 2010;148:544-58.

44. Fischer JP, Wink JD, Tuggle CT, Nelson JA, Kovach SJ, et al. Wound risk assessment in ventral hernia repair: generation and internal validation of a risk stratification system using the ACS-NSQIP. Hernia 2015;19:103-11.

45. Augenstein VA, Colavita PD, Wormer BA, Walters AL, Bradley JF, et al. CeDAR: Carolinas Equation for Determining Associated Risks. J Am Coll Surg 2015;221:S65-66.

46. Otero J, Cox T, Huntington C, Prasad T, Davis BR, et al. Development of the carolinas equation for determining associated risks application and its effects on patient outcomes and potential financial savings in open ventral hernia repair. Am Coll Surg 2018.

47. Hikata T, Iwanami A, Hosogane N, Watanabe K, Ishii K, et al. High preoperative hemoglobin A1c is a risk factor for surgical site infection after posterior thoracic and lumbar spinal instrumentation surgery. J Orthop Sci 2014;19:223-8.

48. Shaw P, Saleem T, Gahtan V. Correlation of hemoglobin A1C level with surgical outcomes: can tight perioperative glucose control reduce infection and cardiac events? Semin Vasc Surg 2014;27:156-61.

49. Liang MK, Holihan JL, Itani K, Alawadi ZM, Gonzalez JR, et al. Ventral hernia management: expert consensus guided by systematic review. Ann Surg 2017;265:80-9.

50. Gatti G, Perrotti A, Reichart D, Maschietto L, Onorati F, et al. Glycated hemoglobin and risk of sternal wound infection after isolated coronary surgery. Circ J 2017;81:36-43.

51. Arya S, Binney ZO, Khakharia A, Long CA, Brewster LP, et al. High hemoglobin Alc associated with increased adverse limb events in peripheral arterial disease patients undergoing revascularization. J Vasc Surg 2018;67:217-28.

52. Sauerland S, Korenkov M, Kleinen T, Arndt M, Paul A. Obesity is a risk factor for recurrence after incisional hernia repair. Hernia 2004;8:42-6.

53. Vidović D, Jurisić D, Franjić BD, Glavan E, Ledinsky M, et al. Factors affecting recurrence after incisional hernia repair. Hernia 2006;10:322-5.

54. Newcomb WL, Polhill JL, Chen AY, Kuwada TS, Kersin KS, et al. Staged hernia repair preceded by gastric bypass for the treatment of morbidly obese patients with complex ventral hernias. Hernia 2008;12:465-9.

55. Schlosser KA, Arnold MR, Kao AM, Augenstein VA, Heniford BT. Building a multidisciplinary hospital-based abdominal wall reconstruction program: nuts and bolts. Plast Reconstr Surg 2018;142:201S-8S.

56. Motz BM, Schlosser KA, Heniford BT. Chemical Components Separation: Concepts, Evidence, and Outcomes. Plast Reconstr Surg 2108; 142:58S-63S.

57. Ueland W, Walsh-Blackmore S, Nisiewicz M, Davenport DL, Pylmale MA, et al. The contribution of specific enhanced recovery after surgery (ERAS) protocol elements to reduced length of hospital stay after ventral hernia repair. Surg Endosc 2019; Epub ahead of print. doi: 10.1007/s00464-019-07233-8

58. Harryman C, Plymale MA, Stearns E, Davenport DL, Chang W, et al. Enhanced value with implementation of an ERAS protocol for ventral hernia repair. Surg Endosc 2019; Epub ahead of print. doi: 10.1007/s00464-019-07166-2

59. Stearns E, Plymale MA, Davenport DL, Totten C, Carmichael SP, et al. Early outcomes of an enhanced recovery protocol for open repair of ventral hernia. Surg Endsoc 2018;32:2914-22.

60. Joseph WJ, Cuccolo NG, Braon ME, Chow I, Beers EH. Frailty predicts morbidity, complication and mortality in patients undergoing complex abdominal wall reconstruction. Hernia 2020;24:235-43.

61. Nilsson E, Haapaniemi S. Hernia registers and specialization. Surg Clin North Am 1998;78:1141-55.

62. Iles JD. Specialisation in elective herniorrhaphy. Lancet 1965;1:751-5.

63. Heniford BT, Walters AL, Lincourt AE, Novitsky YW, Hope WW, et al. Comparison of generic versus specific quality-of-life scales for mesh hernia repairs. J Am Coll Surg 2008;206:638-44.

64. Belyansky I, Tsirline VB, Klima DA, Walters AL, Lincourt AE, et al. Prospective, comparative study of postoperative quality of life in TEP, TAPP, and modified Lichtenstein repairs. Ann Surg 2011;254:709-14.

65. Klima DA, Tsirline VB, Belyansky I, Dacey KT, Lincourt AE, et al. Quality of life following component separation versus standard open ventral hernia repair for large hernias. Surg Innov 2014;21:147-54.

66. Heniford BT, Lincourt AE, Walters AL, Colavita PD, Belyansky I, et al. Carolinas Comfort Scale as a measure of hernia repair quality of life: a reappraisal utilizing 3788 international patients. Ann Surg 2018;267:171-6. 